\title{
Resultados agronômicos e qualitativos da nova cultivar de cevada MN 743
}

\author{
Agronomic and qualitative results of the new barley cultivar MN 743
}

\author{
Eduardo Caierão ${ }^{1}$
}

\section{RESUMO}

A cevada MN 743, criada pela Cia Brasileira de Bebidas (AmBev) foi lançada para cultivo no ano de 2004. Originou-se de um cruzamento simples entre as linhagens MN 681 e GIMPEL, realizado em 1992, no campo experimental da antiga Cia Brahma, no município de Encruzilhada do Sul. A cultivar MN 743 é do tipo duas fileiras, possui ciclo precoce e ampla adaptação às condições do sul do Brasil. Das cultivares disponíveis a nível de produção é a que apresenta a maior classificação comercial (grãos de primeira qualidade). Nos anos em que fez parte do ensaio de Valor de Cultivo e Uso (VCU), sempre apresentou médias competitivas em termos de rendimento corrigido em relação à testemunha de maior área no Brasil, MN 698. Com relação às características qualitativas, apresenta excelente performance no que diz respeito ao teor de extrato e poder diastásico. A cultivar é recomendada para os estados do Rio Grande do Sul, Santa Catarina e Paraná. Devido a seu ótimo desempenho no aspecto qualidade, visando a indústria cervejeira, a cultivar representa um importante avanço para o melhoramento deste cereal no Brasil, aliando os interesses do produtor e da indústria.

Palavras-chave: melhoramento, germoplasma, cereais, Hordeum vulgare.

\section{ABSTRACT}

Barley cultivar MN 743, developed by the Cia. Brasileira de Bebidas (AmBev) was released in 2004 . It resulted from a simple cross between lines MN 681 x GIMPEL, made in 1992, in the Brahma's Experimental Field Encruzilhada do Sul/RS. MN 743, a two-rowed type cultivar has early cicle and is broadly adapted to southern Brazil.
Among the hight producing cultivars available, it shows higher kernel plumpness (first quality kernel). Over the years it was included in the VCU (cost and use value) trial, the cultivar has repeatedly showed competitive means in adjusted yield, as compared to the control occupying the largest cropped area in Brazil, MN 698. Regarding quality characteristics, it has an excellent performance as friability and diastasic power. The cultivar is recomended for all the states of southern Brasil. As a result of its oustanding quality performance, aiming at the brewing industry, MN 743 represents and important breeding step for this cereal in Brazil, combining the goals for both the producer and the industrial sector.

Key words: breeding, germoplasm, cereal, Hordeum vulgare.

A cevada cervejeira é uma excelente alternativa de cultivo para o inverno na região sul do Brasil. Dentre seus principais benefícios, destacamse: precocidade, interferindo de maneira positiva sobre o sistema de produção das propriedades, com a antecipação do plantio da soja (aproveitando a melhor época de semeadura); liquidez, já que o pagamento da produção é realizado logo após a entrega do produto e, rentabilidade, uma vez que o preço do cereal é competitivo com outras culturas de inverno e sua produtividade, na maioria dos anos, tem apresentado médias superiores ao trigo.

Conforme ÁRIAS (1995), a cevada vem sendo cultivada no Brasil desde a década de trinta.

${ }^{1}$ Embrapa Trigo, Rodovia BR 285, km 174, CP 451, 99001-970, Passo Fundo, RS, Brasil. E-mail: caierao@cnpt.embrapa.br. 
Como conseqüência dos esforços do melhoramento genético e do desenvolvimento de técnicas de manejo cada vez mais apropriadas, a cultura foi difundida pelo sul do Brasil, onde se localizam as melhores áreas (em termos de clima e solo) para o desenvolvimento deste cereal. Este incremento ocorreu, também, graças ao trabalho de fomento realizado pelas companhias Brahma e Antártica. Hoje, a produção de cevada no Brasil não é suficiente para atender as demandas da capacidade malteira instalada, originando um déficit, suprido via importação de países como Argentina, Canadá e Comunidade Européia. Mesmo assim, a área de cevada no Brasil oscila entre 100 a 150.000ha há alguns anos. Dentre as principais causas desta variação destacamse a ocorrência de condições climáticas desfavoráveis, principalmente por alta intensidade pluviométrica no momento da colheita (associadas ao fenômeno El nino) (BRAHMA, 1977), e geadas durante e após a floração (MINELLA\& SILVA, 1996; ÁRIAS, 1995), que depreciam a qualidade do produto e promovem a insatisfação dos agricultores.

O programa de melhoramento genético da AmBev, propriamente dito, utiliza diferentes metodologias de condução, desde o método massal até o genealógico, aplicando, inclusive, variações destas metodologias conforme às condições do ano e da própria população segregante. O lançamento de novas cultivares apresenta relação direta com o sistema de fomento deste cereal, já que quando estas não são capazes de compor uma mistura adequada à produção de malte e cerveja, há necessidade de importação de materiais que supram estas deficiências. O lançamento das cultivares MN 684 e MN 698 foi fundamental para a viabilização da cevada nacional, que até então era conhecida como de baixa qualidade malteira; porém, estas apresentavam problemas agronômicos como suscetibilidade ao acamamento e algumas doenças, como Pyrenophora teres.

Este trabalho tem como finalidade informar a comunidade científica e tecnológica sobre a cultivar MN 743, uma cultivar que alia a tradição qualitativa dos materiais da AmBev com melhorias nas características agronômicas. A MN 743 resultou de um cruzamento simples entre as cultivares MN 681 e GIMPEL; a primeira de origem do próprio programa, destaque pelo seu porte e adaptação à diferentes ambientes e, a segunda, americana, com ótimos índices qualitativos. A hibridação foi realizada pela Brahma no ano de 1992 (linhagem CEV 97043), na estação experimental de Encruzilhada do Sul (RS). As gerações segregantes até homozigose foram conduzidas também na Lapa. Até a geração $\mathrm{F}_{4} \mathrm{O}$ material foi selecionado a partir do método massal; nas gerações $F_{5}$ e $F_{6}$, pelo método genealógico. Uma das linhas em geração $\mathrm{F}_{6}$ foi reunida, dando origem a linhagem $\mathrm{CEV}$ 97043, com semente em geração $F_{7}$. Nenhum outro avanço de geração foi realizado posteriormente. O genótipo foi incluído no ensaio preliminar em 1998, regional em 1999, e nacional, em 2000 e 2001 . No ano de 2002, independente das avaliações parciais de qualidade em cada uma destas etapas, o material foi submetido a avaliação qualitativa em escala industrial (requisito para o lançamento e aceitação pela indústria cervejeira) na Maltaria Navegantes, situada no município de Porto Alegre. Em 2003, o malte produzido a partir do processo de malteação foi encaminhado ao Centro de Desenvolvimento Tecnológico (CDT) em Guarulhos/ SP, para avaliação sensorial e organoléptica da cerveja. A aprovação da cultivar para o cultivo comercial foi realizada em dezembro de 2003. Resultados mais detalhados da cultivar estão apresentados nos trabalhos referentes aos ensaios de competição da Comissão Brasileira de Pesquisa de Cevada, editados anualmente (SPEROTTO, 1999, 2000; SPEROTTO \& CAIERÃO, 2001;CAIERÃO, 2002).

\section{Características da cultivar}

Hábito: semi-ereto

Reação à acidez/alumínio: sensível

Acamamento: moderadamente resistente

Reação à doenças: Oídio (Blumeria graminis f. sp. hordei): moderadamente suscetível; Ferrugem da folha (Puccinia hordei): moderadamente resistente; Mancha reticular (Pyrenophora teres): moderadamente suscetível; Mancha marrom (Bipolaris sorokiniana): moderadamente suscetível; Giberela (Fusarium graminearum): suscetível.

Potencial de rendimento: o potencial de rendimento desta cultivar gira em torno de 4 t.ha ${ }^{-1}$. Nos diferentes anos de avaliação, sua média foi de $3.081 \mathrm{~kg} \mathrm{ha}^{-1}$ superando a testemunha MN 698 (Tabela 1).

Classificação comercial: considerando o padrão para recebimento de cevada cervejeira de I Qualidade (grãos

Tabela 1 - Médias de altura, ciclo, classificação comercial e rendimento de grãos da cultivar MN 743 nos 32 diferentes ambientes de avaliação nos últimos 4 anos.

\begin{tabular}{lccc}
\hline Variável & MN 743 & MN 698 (T) & $\begin{array}{c}\text { N }^{\circ} \text { Locais } \\
\text { avaliados }\end{array}$ \\
\hline Altura & 86,3 & $82,9 \mathrm{~cm}$ & 16 \\
Ciclo: espigamento & 88 dias & 90 dias & 16 \\
Ciclo: maturação & 130 dias & 129 dias & 16 \\
Classificação & $89,4 \%$ & $87,1 \%$ & 32 \\
Rendimento & $2.903 \mathrm{~kg} \mathrm{ha}^{-}$ & $2.834 \mathrm{~kg} \mathrm{ha}^{-}$ & 32 \\
\hline
\end{tabular}

Fonte: Relatório Gerencial - AmBev, 2004 
superiores a 2,5mm), a média da cultivar nos ambientes testados foi de aproximadamente 88\% (Tabela 1).

Qualidade industrial do malte: todos os testes realizados durante a fase de experimentação (500g) e micro-maltaria (800kg de cevada) conferem à cultivar padrão cervejeiro (Tabela 2).

Em 2004, foram cultivados aproximadamente 1.900ha da cultivar no estado do Rio Grande do Sul. Seu desempenho foi considerado muito bom, com perspectiva de incremento de área. Estima-se que a área para 2005 represente em torno de $10 \%$ do fomento realizado pela Cia Brasileira de Bebidas (AmBev).

Tabela 2 - Resultado qualitativo da cultivar MN 743 com relação ao teor de proteína (\%), teor de extrato (\%), poder diastásico (Wk), teor de b-glucanas (mg $100 \mathrm{~g}^{-1}$ ) e friabilidade (\%) obtidos do processo de micromalteação realizado na Maltaria Navegantes, em 2003.

\begin{tabular}{lccl}
\hline Variável & Unidade & MN 743 & Especificação \\
\hline Teor de proteína & $\%$ & 11,4 & de 10,5 a 12,5 \\
Teor de extrato & $\%$ & 81,0 & Mínimo 80,5 \\
Poder diastásico & Wk & 374 & Mínimo 220 \\
B-Glucanas & mg 100g-1 & 190 & Máximo 180 \\
Friabilidade & $\%$ & 78 & Mínimo 75 \\
\hline
\end{tabular}

Fonte: Laboratório Maltaria Navegantes - Cia Brasileira de Bebidas, 2003.

\section{REFERÊNCIAS}

ÁRIAS, G. Mejoramiento genético y produción de cebada cervecera en América del Sur. Santiago: FAO, 1995. 157p.

BRAHMA. A Brahma e a cevada no Brasil. [S.1.], 1977. 36p.

CAIERÃO, E. Ensaios finais conduzidos pela AmBev em 2001. In: REUNIÃO ANUAL DE PESQUISA DE CEVADA, 22., 2002, Passo Fundo/RS. Anais... Passo Fundo: EmbrapaCNPT, 2002. p.28-299.

MINELLA, E.; SILVA, M.S. Breeding barley for aluminum tolerance in Brazil. In: INTERNACIONAL OAT CONFERENCE, 5., INTERNATIONAL BARLEY GENETICS SYMPOSIUM, 7., 1996, Saskatoon. Proceedings: poster sessions. Saskatoon: University of Saskatchewan, 1996. V.2, p.528-529.

SPEROTTO, A.L. Ensaio CEV conduzido na região sul do Rio Grande do Sul - 1998. In: REUNIÃO ANUAL DE PESQUISA DE CEVADA, 19., 1999, Passo Fundo/RS. Anais... Passo Fundo: Embrapa-CNPT, 1999. p.216-224.

SPEROTTO, A.L. Ensaios intermediários de cevada conduzidos na região sul do Rio Grande do Sul - 1999. In: REUNIÃO ANUAL DE PESQUISA DE CEVADA, 20., 2000, Passo Fundo/RS. Anais... Passo Fundo: Embrapa-CNPT, 2000. p.238-245.

SPEROTTO, A.L.; CAIERÃO, E. Ensaios finais de cevada pela AmBev em Piratini, Sananduva, Papanduva, Campos Novos e Lapa, 2000. In: REUNIÃO ANUAL DE PESQUISA DE CEVADA, 21., 2001, Passo Fundo/RS. Anais... Guarapuava: Cooperativa Agrária, 2001. p.295-308. 